\title{
Políticas de Maturação Às Estratégias Locacionais das COMPanHias Multinacionais Automotivas e ao Sistema Nacional de InOVaÇão
}

\author{
José Carlos de Jesus Lopes \\ Doutorando em Meio Ambiente e Desenvolvimento \\ pela Universidade Federal do Paraná - UFPR. \\ Doutorando em Ciências Empresariais, pela \\ Universidade do Sul de Sana Catarina - UNISUL e \\ Universidad del Museo Social de Argentina - UMSA. \\ Professor de Graduação e de Pós-Graduação (Especialização) \\ jclopes@wnet.com.br
}

\section{RESUMO}

Objetiva-se neste trabalho fazer uma análise sobre as futuras políticas complementares para a maturação dos Clusters automotivos, implantados na Região Metropolitana de Curitiba - RMC. A problemática deste artigo está centrada na necessidade de constantes implementações de inovações tecnológicas para que ocorra a maturação dos aglomerados industriais localizados na RMC. Este artigo está fundamentado por autores, que tratam da globalização e da aglomeração industrial vigente. O ponto central passa pelo diálogo sobre o modo de produção capitalista, tendo como base as novas estratégias locacionais dos complexos industriais automotivos, por conta da formação da aglomeração industrial - cluster. Ao longo desta pesquisa, foi possível antever, de forma estratégica, a necessidade de implantação de novas políticas de maturação, por conta das instituições responsáveis pela manutenção dos clusters automotivos nas regiões politicamente delimitadas, tal como na RMC.

Palavras-chave: Aglomeração industrial - Cluster. estratégias locacionais. Sistema nacional de inovação. Companhias automotivas. Produção flexível.
This paper is intended to analyze the future complementary policies to the maturation of automotive clusters that have been implanted in the Metropolitan Region of Curitiba.$M R C$. The problem brought up in this article concerns the need of constant implementations and technological innovations to promote the maturation of industrial clusters located at the MRC. This article is based on authors who have studied the globalization process and the effective industrial agglomeration. Thus, the main point involves the dialogue on the capitalist manner of production based on the new location strategies of automotive industrial complexes on account of the formation of industrial agglomeration cluster. Throughout this research, it was possible to strategically foresee the necessity of having new maturation politicies implantated by the institutions responsible for the maintenance of the automotive clusters in the regions politically delimited, such as in the MRC.

Key words: Industrial Agglomeration - Cluster. Locational strategies. National innovation system. Automotive companies. Flexible production. 


\section{INTRODUÇÃO}

É a partir da década de oitenta do século passado, que o mundo começa a perceber que está em vigor uma nova divisão internacional do trabalho, sendo protagonizada pelas Companhias Multinacionais - CMNs, sob o manto da globalização da produção, desta vez, por conta da produção flexível, que resulta num outro aspecto na economia mundial. De acordo com Santos (2002, p. 29), as principais características dessa nova economia mundial estão fundamentadas em:

economia dominada pelo sistema financeiro e pelo investimento à escala global; processos de produção flexível e multilocais; baixos custos de transportes, revolução nas tecnologias de informação e de comunicação, desregulação das economias nacionais; preeminência das agências financeiras multilaterais; emergência de três grandes capitalismos transnacionais.(SANTOS, 2002, p. 29).

Observa-se, naquele período até os dias de hoje, que tais transformações que interagem em todo o sistema mundial, ainda que com intensidade desigual de acordo com a posição dos países no sistema mundial, promovem pressões e implicações nas políticas nacionais, que forçam os governos a abrir as suas economias para o mercado mundial. Precisa ser igualmente promovido, a produção interna para a exportação, além de criar estímulos para a privatização dos empreendimentos estatais.

Os estados federativos necessitam também promover instrumentos de atração dos investimentos diretos estrangeiros, por conta da liberação do seu mercado doméstico e da regulação do fluxo financeiro do excedente. A competitividade de inserção no mercado internacional não se dá somente através das organizações privadas; mas, igualmente, pelos países, através dos seus estados federativos, que começaram a competir entre si, para atrair os novos investimentos derivados dos caixas das empresas multinacionais, dada a incapacidade dos governos centrais em poder financiar diretamente os projetos de crescimento econômico nacional.

Por força da necessidade de internacionalização não só da economia brasileira, bem como a economia dos estados federativos da união, o estado do Paraná, durante as décadas de 60 e 70, desenvolveu diversos projetos para promover o crescimento econômico, através das construções de parques industriais, com o intuito de atrair os investidores estrangeiros. Mais especificamente, no período 1995-2000, o Estado do Paraná participou da concorrência industrializante, objetivando atrair para as regiões paranaenses, uma parcela dos investimentos empresariais globais.

Face às políticas e dos programas do Governo de Estado implementados, como fator de captação destes investimentos privados, são criados na Região Metropo- litana de Curitiba - RMC, alguns conglomerados industriais, tendo destaque a instalação de algumas montadoras de automóveis, indústria de transformações e as empresas motrizes que fazem parte da cadeia produtiva destes segmentos.

Lemos e Ferreira (2004) desenvolveram um trabalho científico, intitulado "Novas Estratégias Locacionais das CMNs Automotivas e Sistema Nacional de Inovação da Periferia Industrializada", que aborda exatamente a forma como as montadoras automotivas se instalaram no Brasil, dando ênfase no período que abrange 1985 a 2000. É neste período que se observa uma mudança locacional estratégica das montadoras de automóveis, bem como demanda novo sistema de inovação na periferia industrializada. O Brasil conseguiu atrair parte destes investimentos estrangeiros diretos, que se aglomeraram em determinadas regiões produtivas.

Outra pesquisa, que substancia o presente trabalho, é de Cunha et al (2004), intitulado "Clusters, Novo Padrão de Especialização da Indústria Paranaense na Década de 90", que objetivou identificar as especificidades delineadas pelo novo padrão de industrialização da economia paranaense e seus rebatimentos em termos da reorganização espacial da indústria. A questão central da investigação proposta dizia respeito à identificação das mudanças estruturais no padrão de aglomeração espacial das indústrias do Paraná, nos anos 90, utilizando o recorte analítico baseado no conceito de clusters.

Neste contexto, surge o objetivo deste trabalho, que é fazer uma análise sobre as futuras políticas complementares para a maturação dos Clusters automotivos, implantados na Região Metropolitana de Curitiba - RMC. Um dos objetivos específicos é fazer, portanto, algumas análises baseadas nas pesquisas realizadas por Lemos e Ferreira (2004) e Cunha et al (2004), que tratam das novas estratégias locacionais das CMNs automotivas e do sistema nacional de inovação na periferia industrializada, e ampliar uma possível discussão em alguns tópicos que merecem destaques.

Para tanto, faz-se necessário, apresentar, a seguir, as principais partes das pesquisas que serviram de base para o objetivo proposto. Faz-se, ainda, necessário destacar que a principal razão deste trabalho não é invalidar as propostas das pesquisas, inicialmente, realizadas pelos autores citados; mas sim, dar continuidade às reflexões contidas nas investigações científicas; porém agora, de forma interdisciplinar, tal como propõe Leff (2000).

\section{A força da inovação tecnológica nos arranjos produ- tivos}

Lemos e Ferreira (2004) analisaram as conseqüências das novas tecnologias, principalmente as que se relacionam com a microeletrônica, sobre as novas estratégias locacionais das corporações multinacionais, na reconfiguração espacial da indústria automobilística, par- 
ticularmente, nos países periféricos de industrialização recente, com sistemas nacionais de inovação incompletos. O objetivo da pesquisa dos autores foi entender o duplo movimento locacional ocorrido no Brasil, procurando identificar a nova configuração geográfica da indústria automotiva brasileira, no período 1985 a 2000 , através da delimitação das principais microrregiões que ganhavam atratividade nesse processo.

No corpo do trabalho foram destacados alguns entendimentos, por exemplo, sobre o movimento, que é bastante dinâmico, da concentração de atividades produtivas em determinadas localidades, que eventualmente pode resultar em centralização espacial da tomada de decisão das empresas. Os autores perceberam que, de forma geral, a dispersão geográfica tem ocorrido em nível das divisões operacionais, especialmente na esfera da produção material de bens tangíveis; embora, de regra geral, a inteligência da empresa se mantenha centralizada nos países do Norte.

Foi destacado, num capítulo do trabalho, a percepção que em meio a tantas transformações e adaptações, a indústria automobilística mundial apresentou respostas bastante diversificadas, destacando-se competitivamente, quando passou a adotar o sistema produtivo de automação flexível, afastando-se do sistema produtivo de automação rígida. Este último, também denominado de pós-fordismo, que se baseava na produção de massa, foi substituído por sistemas integrados de produção enxuta, sistema conhecido de sistema toyotista, que adotam técnicas e ferramentas do just in time, trabalho em equipe, qualidade total, dentre outras implementações de novas gestões organizacionais e produtivas.

O sucesso desse novo sistema de produção flexível está amparado pela formação de novos arranjos produtivos interfirmas, baseados na redefinição das relações entre as empresas montadoras e os fornecedores de autopeças, na concentração setorial de capital e na centralização das decisões intra-cadeia, tal como se define o sistema de cluster. Os autores destacam:

O processo produtivo passa a ser realizado por meio de operações modulares, controladas e coordenadas, representando uma forma complexa de integração, baseada na conjunção entre especialização e capacidade de adaptação às mudanças impostas pelo sistema econômico, de modo que se tenha a minimização dos custos de transação, maior controle de qualidade, criação e acúmulo de conhecimento dentro da cadeia, decomposta em diversos arranjos produtivos locais (LEMOS; FERREIRA, 2004, p. 4).

Por último, os pesquisadores enfatizam que o processo recente de localização da indústria automotiva reflete a combinação de dois movimentos. O primeiro refere-se à relativa dispersão mundial e regional da esfera produtiva. O segundo consiste na concentração industrial intra-regional, em nível micro-locacional dos arranjos produtivos locais. No caso brasileiro, verificou-se, que nos últimos anos, houve uma relativa dispersão regional, porém geograficamente limitada e setorialmente restringida.

Lemos e Ferreira (2004) finalizam suas análises, alertando que, se a nova delimitação da indústria, que representa uma desaglomeração produtiva em direção ao entorno próximo de polarização da metrópole paulista, tais como os clusters automotivos localizados nos estados de Minas Gerais, Paraná e Rio Grande do Sul; logo, as montadoras, que se situam fora do polígono de desenvolvimento do Sul-Sudeste, tendem a correr sérios riscos de sustentabilidade econômica de longo prazo, após cessar os benefícios fiscais, que foram os condicionantes decisivos para a atração das montadoras para aquelas localizações.

É, portanto, a partir deste alerta, que se cria a problemática agora levantada para este artigo. Indaga-se: a preocupação deve apenas se centralizar nas montadoras que estão instaladas fora da polarização da metrópole paulista? Será que as montadoras que escolheram tecnicamente localizar-se na RMC não correm igualmente o mesmo risco de não serem sustentáveis economicamente, no longo prazo, após o encerramento dos incentivos fiscais ofertados pelo governo do estado do Paraná?

Não será necessário, que as instituições responsáveis pela atração destes investimentos estrangeiros para o estado do Paraná ainda precisem implementar novas políticas institucionalizadas para a maturação destes empreendimentos? Eis o desafio do autor deste trabalho, que não tem por objetivo dar uma resposta definitiva; mas, sim, levantar tais questionamentos e propor reflexões sobre até que ponto as empresas automotivas estrangeiras estão efetivamente consolidadas na RMC, por conta desta nova configuração espacial.

\section{A globalização e suas diversas (a)versões abrangentes}

O tema globalização tem sido exaustivamente discutido em centenas de literaturas ao redor do mundo. As reflexões de Giddens (1991), Chesnais (1996), Beck (1997), Dupas (1999), Leff (2000), Santos (2002), Castells (2002), Wallerstein (2002) e Floriani (2004) merecem destaques, pois fazem profundas reflexões das inter-relações desse processo. Por mais que o tema globalização seja bastante analisado pela ótica econômica, os autores alertam que o processo de globalização ou de mundialização precisa ser analisado igualmente pelas demais ciências.

Para os autores o processo de internacionalização das atividades comerciais tem sua origem a partir do século XV. Durante alguns séculos, o modo de produção capitalista, por conta de conquista e ampliação de novas terras, mercados, fortaleciam o poder econômico e políti- 
co daqueles que detinham os meios de produção. Desde então, esse modo de expansão das atividades industriais e dos demais setores e segmentos chaves derivados se apresentam com diferentes intensidades.

Wallerstein (2002) acredita que a partir da Primeira Revolução Industrial e, com mais vigor, nas últimas três décadas do século XX, que o processo que passa a ser denominado de globalização, ganhou mais ênfase, com modelos de intervenção e consolidação de forma diferenciada e mais abrangente e complexa. É a partir também desse período, que os estudiosos de diversas áreas do conhecimento, tais como os sociológicos começaram a se debruçar mais sobre este tema.

A esse respeito, Floriani (2004) discute a globalização, reconhecendo que este processo reflete as mazelas sociais existentes nas diversas e longínquas regiões do planeta, derivadas do antigo sistema colonial, que tem desde então proporcionado a uma pequena classe produtiva e consumidora global uma constante e crescente concentração de riqueza e poder em detrimento de outras largas classes sociais igualmente globais. Estas últimas em franca desproporção dos resultados aferidos desse fenômeno.

Para Floriani (2004); embora, os diversos estudos sobre a globalização tenham sido analisados sob a ótica dos aspectos econômicos, não se deve esquecer que o termo é muito mais amplo, abrindo assim, a possibilidade do processo de globalização ser igualmente analisado interdisciplinarmente, não somente pela economia, mas também e igualmente necessária pela geografia, sociologia, ciência política, antropologia, demografia, ecologia, direito, ecologia, filosofia, dentre outras ciências, mantendo o que o autor em apreço chama de "diálogo de fronteira". Diz ele:

Assim, para o caso das recém consideradas 'ciências ambientais', trata-se mais bem de ensaios no interior de algumas disciplinas, ou melhor, de alguns temas disciplinares que buscam compor um aglomerado de saberes, buscando sintetizar alguns resultados, na confluência dos conhecimentos das ciências naturais e das ciências sociais, ao realizarem estudos que exigem uma maior aproximação das ciências da vida, da natureza e da sociedade. (FLORIANI, 2004, p. 52).

O autor ainda destaca importância de tratar a globalização como questão para a discussão e para a ação política no interior dos movimentos sociais e em outras instituições coletivas, uma vez que esse debate tem sido travado por conseqüência da modernidade e suas crises, algo contraditório. Para o mesmo autor, a sociedade moderna fundamentou-se na tríplice: 1) conhecimento; 2 ) meio ambiente; e 3 ) globalização.

É através do conhecimento, que o homem tem potencializado o seu intelecto, interdependendo cada vez mais da tecnologia. É do meio ambiente, da natureza que o homem extrai todas as matérias primas que necessita, desde os bens materiais aos imateriais. Globalização, pois foi através das trocas desiguais, entre os povos, países e blocos econômicos, que constituiu e institucionalizou uma sociedade capitalista, auto intitulada moderna. Reconhece-se que é um mundo moderno, uma sociedade moderna, sem dúvida, porém muito complexa. Utilizando-se ainda mais das reflexões de Floriani (2004), vale ressaltar que:

Sinônimo de globalização, as sociedades complexas de hoje se articulam e desarticulam em escala planetária, por onde se constroem novos sentidos e desconstroem outros; conflitivamente disputados e ameaçados pela modernidade em risco; acossada pela tradição alterada, essa modernidade é marcada pelo signo da incerteza que habita nos interstícios da complexidade. (FLORIANI, 2004, p. 10).

Nestas condições, há inúmeras complexidades e contradições: conhecimento sendo direcionado para a crescente concentração da produção das organizações produtivas, agora sob o manto da produção flexível, e financeiras transnacionais; recursos naturais degradados, centenas de espécies de animais e de outros seres vivos extintos; matérias primas finitas, num planeta finito; globalização produzindo concentração da renda global para poucos, em detrimento da pobreza, miséria, poluição, desnutrição, prostituição, narcotráfico de drogas, terrorismo (nos seus diversos formatos) para a maioria da população global.

Giddens (1991, p. 13), ao analisar o processo de globalização, diz que: "a globalização pode ser definida como a intensificação das relações sociais em escala mundial, que ligam localidades distantes". Dupas (1999) esclarece que, a partir da década de 1980, observa-se uma intensificação do processo de internacionalização das economias capitalistas que se convencionou chamar de "globalização", sendo que o capitalismo atual é alimentado pela força das suas contradições: a primeira provoca o "processo de concentração"; a segunda promove a "dialética exclusão versus inclusão".

O primeiro fenômeno, o da concentração, é formado por uma enorme escala de investimentos necessários à liderança tecnológica de produtos e processos e a necessidade de networks e mídias globais, que habilitará como líderes das principais cadeias de produção apenas um conjunto restrito de algumas centenas de empresas gigantes mundiais. Enfatiza Dupas (1999, p. 78) que "são essas corporações que decidirão basicamente o que, como, quando, quanto e onde produzir os bens e serviços demandados pela sociedade contemporânea".

O segundo, a da dialética exclusão versus inclusão, provoca em espaços diferentes o desemprego estrutural, 
po a inclusão, pois oportuniza a inserção dos produtos e serviços globais a determinados núcleos de consumidores em determinados países, que estavam à margem do consumo, seja por restrições orçamentárias, seja por decisões políticas das economias semi-fechadas.

Chesnais (1996) prefere chamar de mundialização, o processo aqui anteriormente denominado de globalização, uma vez que a produção não está distribuída em todo o globo e que nem todos os povos têm acesso a essa produção. São as empresas que estão distribuídas em alguns países, que ofereçam condições propícias às instalações de suas filiais. Por conta deste modelo, o mesmo autor identifica o processo da globalização como algumas poucas ilhas de prosperidades e imensos continentes de pobreza. Ainda continuando com o entendimento de Chesnais (1996, p. 25), "o crescimento das economias dos países pobres ou em desenvolvimentos fica vulnerável às decisões tomadas nos "boards" dos executivos das empresas multinacionais". Prossegue, ele explicando que "são as empresas que decidem quais são os países ou regiões da vez de crescer ou empobrecer cada vez mais".

Em outras palavras, o pensador parece fazer um diagnóstico para o futuro dos países, pois só crescerão economicamente, os países, ou regiões, que essas organizações possam optar por instalar os seus investimentos, as suas operações produtivas ou mercantis. Por conta deste entendimento, o Estado-Nação perde a força de indução de investimentos. Por outro lado, o Estado passa a cumprir um outro papel.

Desta forma, e sob a égide do livre mercado, pressuposto do neoliberalismo, fatores produtivos, a exemplos das imensas reservas de recursos naturais, combinados com mão de obra barata, porém qualificada, além das leis fiscais e ambientais flexíveis, bem como o desejo da internacionalização dos países pobres, portanto, uma decisão política; todos esses fatores, quando politicamente combinados e amparados por forças institucionais, são traduzidos pelo capital internacional, como oportunidades de negócios, no sistema produtivo periférico global.

Através dessas decisões tomadas nas mesas dos executivos das mega organizações, apoiadas por organismos internacionais, que algumas regiões econômicas participam do processo da globalização e outras regiões que serão excluídas, bem como as sociedades nelas inseridas. É dentro deste contexto, que se criam as organizações humanas, que aderem ao sistema e outras que o rejeitam, o que Floriani (2004) chama as primeiras de globalfílicas e as segundas de globalfóbicas; ou seja, as amantes e detratores da globalização, respectivamente.

Floriani (2004) ao concordar com Dupas (1999) e Chesnais (1996) sintetiza que tais situações são assimétricas de produção, comercialização, consumo e apropriação dos recursos naturais e que desenham de maneira bipolar a concentração de riqueza. Cita-se, como exemplo, sem muita dificuldade, a hegemonia econômica, política e bélica dos Estados Unidos da América do Norte, ao recepcionar os demais membros do G-7, no Fórum Econômico de Davos, em 2002; e em paralelo, coincidentemente ainda na América do Sul, o Brasil recepciona os demais membros do G-77, no Fórum Social Mundial, em Porto Alegre, fazendo oposição ao neoliberalismo globalizante.

A esse respeito, Beck (1997) reconhece que o modo de produção capitalista, bem como o crescimento desordenado da população mundial causa impactos sobre o esgotamento dos recursos não renováveis. Reconhece ainda o autor, que a sociedade moderna acredita na tecnologia como instrumento que abre a possibilidade de todos os recursos naturais não renováveis e finitos, mesmo num espaço finito como é o Planeta Terra, tornarem recursos renováveis e infinitos por conta da substituição dos fatores produtivos. Pensa ainda o autor, que o paradigma tecnológico é a base da sociedade moderna. Os cientistas que o promovem, bem como as instituições que o apóiam precisam promover uma modernização reflexiva, no contexto da globalização. Continua o mesmo autor a se expressar:

Modernização reflexiva significa a possibilidade de uma (auto)destruição criativa para toda uma era: aquela da sociedade industrial. O sujeito dessa destruição criativa não é a revolução, não é a crise, mas a vitória da modernização ocidental [...] Se, no fundo, a modernização simples ou ortodoxa significa primeiro a desincorporação e, segundo, a reincorporação das formas sociais tradicionais pelas formas sociais industriais, então a modernização reflexiva significa primeiro a desincorporação e, segundo, a reincorporação das formas sociais industriais por outra modernidade. Por isso, supõe-se que modernização reflexiva signifique que uma mudança da sociedade industrial - ocorrida sub-repentinamente e sem planejamento no início de uma modernização normal, autônoma, e com uma ordem política e econômica inalterada e intacta - implica a radicalização da modernidade, que vai invadir as premissas e os contornos da sociedade industrial e abrir caminhos para outra modernidade. Beck (1997, p. 12-13).

Concordando com Floriani (2004) e Giddens (1991), que não são contra a modernização, Beck (1997) enseja que haja uma modernização mais reflexiva, uma vez que esse modelo tecnológico traz consigo riscos. Por sua vez, Giddens (1991) indaga, ao se confrontar com a possibilidade dos cientistas poderem efetivamente avaliar, medir e controlar os efeitos colaterais derivados do desenvolvimento tecnológico: 


\section{Reavaliando as propostas da aglomeração industrial - Clusters}

Os primeiros estudos clássicos sobre aglomeração industrial foram realizados por Marshall (1982), que analisou os resultados positivos, quando as empresas que constituíam uma determinada indústria, buscam se instalar senão numa única localização, mas que cujas localizações fossem muito próximas uma das outras, dentro de uma região definida estrategicamente.

Com o aprimoramento das gestões organizacionais, por força da competição global, as empresas buscavam e continuam buscando incessantemente novas estratégias locacionais, tendo como apoio as instituições públicas, que desejam promover, igualmente, o desenvolvimento local ou regional. A estratégia da concentração locacional das indústrias, por conta dos novos arranjos produtivos, passou a ser chamada, no meio acadêmico, de cluster.

Nos trabalhos de Suzigan (2000-a; 2000-b) e Garcez (2000), os autores e seus colaboradores fazem a distinção entre distrito industrial e cluster. Para eles, distrito industrial é um modelo de gestão da cooperação no aspecto produtivo, de comunicação e disseminação de tecnologias entre pequenas e médias empresas, que resultam na economia de escala e de escopo.

Por conta desta estratégia, as pequenas e médias empresas reduzem custos, ganham flexibilidade e tornam-se mais competitivas do que as grandes empresas; ou na maioria das vezes, organizam-se para fazer frente às pressões das grandes empresas. Este modelo particular de desenvolvimento industrial foi praticado nos anos 70 e 80 na Itália.

Garcez (2000) percebe uma estratégia de cluster "quando há uma concentração setorial e geográfica de empresas". Uma vez implantada esta concentração devem surgir externalidades, por conta de instalações na região de novos fornecedores de matérias primas e componentes, novos maquinários, além dos trabalhadores com habilidades específicas em determinados setores. A disseminação das tecnológicas envolvidas nas gestões precisam ser precisas e contínuas.

Suzigan (2000) alerta, no entanto, que há várias abordagens ao tema de industrial clustering, tais como: 1) aos que se inspiram na experiência dos distritos industriais italianos ou europeus, de modo geral; 2) as que se baseiam na natureza localizada da inovação tecnológica na dinâmica industrial; 3) as que se fundamentam na economia regional para estabelecer relação entre geografia econômica e desempenho industrial; 4) as que focalizam estratégias das empresas na busca de vantagens competitivas geograficamente restritas; e 5) da nova abordagem da geografia econômica.

Parece que todas as cinco abordagens, mencionadas por este último autor, fazem parte do escopo das análises aqui propostas, no que tange a aglomeração industrial na Região Metropolitana de Curitiba - RMC. Continua
Suzigan (2000), dizendo que Krugman (1991) construiu um modelo analítico em que a evolução da estrutura espacial da economia é determinada pelo confronto entre as forças centrípedas (representadas pelos linkages, mercados densos, spillovers de conhecimentos e de outras economias externas puras), que induzem a concentração espacial de atividade econômica, e por forças centrífugas (representado por fatores fixos ou imobilizados, aluguéis e custos de commuting, congestionamento, poluição e outras deseconomias externas puras), que desestimulam a concentração industrial.

Altenbung e Mayer-Stamer (apud SUZIGAN, 2000, p. 33) postulam que cluster, num sentido amplo, apenas "retrata concentrações locais de certas atividades econômicas". A definição operacional "consiste numa aglomeração de tamanho considerável de firmas numa área espacialmente delimitada com claro perfil de especialização e na qual o comércio e a especialização inter-firmas são instrumentos substanciais para a manutenção das bases".

Neste ponto, Gualda (2004), que também difere distrito industrial de um cluster, entende, que um cluster, de forma geral, promove uma associação de atividades semelhantes, que se desenvolvem conjuntamente. Assim sendo, o conceito sugere a idéia de junção, união, agregação, integração. Em outras palavras, um cluster seria algo como um sistema, tal como uma colméia, formada por elementos de cooperação, colaboração, especialização, por conta de uma divisão do trabalho. Por fim, as estratégicas do cluster podem ser aplicadas para objetivar políticas de macroeconomia dos Estados, igualmente por micro políticas das empresas.

Para ele, do ponto de vista de macro-políticas públicas, o modelo de aglomeração industrial, torna-se uma nova forma estratégica que atingir o desenvolvimento econômico e social em diversas regiões ao redor do mundo. Observa-se que tais decisões estratégias são utilizadas por instituições públicas, bem como as privadas, tanto nos países Norte, como nos países Sul. Tal decisão política e empresarial é uma justificativa para dar resposta urgente à demanda do processo de globalização, que é cada vez mais crescente. A definição da região onde serão implantadas as aglomerações industriais pode acontecer de forma natural, ou seja, por força próprio mercado ou delimitado, através dos projetos públicos institucionalizados, que buscam promover o desenvolvimento econômico no local ou região politicamente indicada.

Face à uma política de desenvolvimento de uma região econômica, a implantação de um sistema de clusters, quando estrategicamente institucionalizada pelo Estado e por demais instituições de apóio, precisa promover os aglomerados de atividades industriais afins, localizadas em determinado espaço geográfico e desenvolvidos por empresas autônomas de pequeno, médio e até de grande 
porte, intensamente articuladas, constituindo ambiente de negócios onde prevalecem relações de recíproca confiança entre as diferentes partes envolvidas.

As empresas, que participam desse modelo de arranjo produtivo, precisam, portanto, estar apoiadas por instituições provedoras de recursos humanos, de recursos financeiros, de infra-estrutura, bem como de políticas de aprimoramento dos projetos já implantados. Numa estratégia microeconômica e empresarial, o cluster pode ser considerado como a reunião de pequenas ou médias empresas, às vezes até mesmo as de maior porte, que estão situadas num mesmo local e que apresentam grandes níveis de entrosamento entre si, e constituem o que hoje existe de mais moderno em modelo de desenvolvimento local. Reposicionando as colocações de Gualda (2004), para que um sistema de arranjo produtivo possa assumir as características de um cluster, precisa, necessariamente, atender aos seguintes requisitos:

Aglomeração - significa idéia de conjunto inter-relacionado e espacialmente concentrado, ensejando a troca de sinergia e a prática de cooperação e de alianças estratégicas, inclusive para neutralizar limitações relacionadas a economias de escala, como processos tecnológicos, aquisições de insumos, assistência técnica;

Afinidade - as empresas envolvidas precisam estar voltadas para o mesmo ramo de negócio (atividade principal do cluster), embora cada uma (ou um conjunto) delas se especialize em tarefas específicas (fornecimento de insumos e serviços, produção, comercialização, pesquisa, desenvolvimento de novos mercados, dentre outras gestões);

Articulação - propõe um relacionamento próximo, intensivo e permanente entre as empresas, propiciando, por um lado, a troca de sinergia e a prática da colaboração e, por outro, estimulando a rivalidade e a competição;

Cooperação - as relações comerciais são apoiadas na confiança recíproca, condição favorável à formação de parcerias e de alianças estratégicas, através das quais as partes envolvidas, mesmos os concorrentes, unem-se para enfrentar problemas comuns de logística, de assistência técnica, de comercialização, de suprimento de matérias-primas e de insumos;

Poder de negociação e representação - organizam-se para negociar com o governo e com instituições públicas e privadas, ações consideradas importantes para o fortalecimento e a consolidação do cluster;

Apoio Institucional - formado por uma rede de ins- tituições públicas, privadas e até ONG's, que atuam em torno do cluster como estimuladoras e catalisadoras da integração e da colaboração dos atores (governo em todos os níveis e iniciativa privada), inclusive mediando eventuais conflitos de interesses entre as firmas/instituições, tendo em vista a sustentabilidade do processo no longo prazo.

Diante do entendimento da lógica dos clusters, fica evidente, e conforme postulado por diversos autores, quando bem implementadas as gestões de implantação, bem como as gestões de manutenção dos projetos, o resultado da estratégia de aglomeração industrial possibilita diversas oportunidades de ganhos e de competitividade para as empresas instaladas nas regiões técnica e politicamente selecionadas.

Em conjunto, necessita-se, igualmente, potencializar a racionalização das estratégias administrativas, comerciais, logística, da diminuição dos custos de transportes, comunicação, mão-de-obra, deslocamentos, além dos diversos ganhos de economia de escala ou ainda mesmo na economia de escopo. Iguais resultados econômicos poderão ser auferidos pela sociedade e pelos gestores do Estado, que adotaram tais instrumentos para o desenvolvimento de determinadas regiões.

Isto posto e por conta das reflexões desenvolvidas até aqui, vale a pena recorrer ao alerta que faz Wallerstein (2002) faz, quando diz que o fato de um Estado desenvolver projetos de desenvolvimento de determinadas regiões é uma condição necessária, mas não suficiente para atrair o interesse das CMNs. Outros fatores de produção interferem na tomada de decisões dos empresários.

Em suma, o que atrai mesmo o interesse das CMNs é a necessidade constante da busca da maximização do lucro; pois, quando, os executivos percebem que determinadas regiões exploradas, por fatores exógenos e endógenos diversos, tendem a produzir resultados econômicos declinantes, começam a investigar novas regiões geográficas, novas localizações espaciais, ainda não exploradas, que possam ser palco do reinício da reprodução do capital. Esclarece o próprio autor:

Toda vez que há estagnação da economia internacional e um estreitamento dos lucros em geral, e do das atividades produtivas em particular, alguma região geográfica, que até esse momento não se encontrava no topo da hierarquia quanto a geração de lucro, passa a ter resultados muito bons. Ela se converte em pólo atrativo para amplos movimentos de relocalização da produção do mundo todo, beneficiando-se das dificuldades da economia internacional em conjunto. (WALLERSTEIN, 2002, p. 66-67). 


\section{Necessidades de políticas de manutenção e aprimo- ramento das estratégias da indústria automotiva na RMC}

Conforme analisado anteriormente, que as estratégias de desenvolvimento de concentração industrial e o fortalecimento dos clusters definem-se pelo envolvimento dos agentes locais públicos e privados como condutores da promoção da industrialização local. Os agentes locais, representados pelas instituições públicas locais, associações empresariais, universidades e instituições de pesquisas e as empresas devem ter um papel pró-ativo na potencialização dos fatores determinantes da transformação regional e da sua competitividade sistêmica.

Estes fatores foram destacados por Cunha et al. (2004, p. 3) num trabalho intitulado "clusters: novo padrão de especialização da indústria paranaense, na década de 90 ". A questão central da investigação diz respeito à identificação das mudanças estruturais no padrão de aglomeração espacial das indústrias do Paraná, nos anos 90, utilizando o recorte analítico, baseado no conceito de clusters, caracterizado pela concentração industrial. Face aos resultados da pesquisa, verificou-se que as inversões produtivas realizadas nos últimos vinte anos no estado do Paraná apontam duas tendências. A primeira, por conta do processo de implantação das unidades montadoras automobilísticas, no Estado, mais precisamente na RMC, que resultou num adensamento da matriz de relações inter-industriais e inter-firmas.
Os autores comprovaram, que tais estratégias têm possibilitado uma elevação no fluxo das compras regionais e estimulando as empresas locais a aumentarem a densidade tecnológica nos processos produtivos e organizacionais, por conta das parcerias com empresa estrangeiras e/ou através de investimentos em pesquisa e desenvolvimento - P\&D. Igualmente, por conta desta estratégia, a implantação das montadoras vem atraindo companhias multinacionais, empresas fornecedoras de insumos e matérias primas, com perspectiva de atender ao mercado local, nacional e mesmo internacional.

Assim, a partir da segunda metade da década de 90, a RMC, consolida-se como uma das aglomerações industriais de destaque em nível nacional, como previra o projeto de desenvolvimento da RMC. Os autores da pesquisa acreditam, que esses novos investimentos vêm acompanhados pela maior diversificação industrial, pela expansão dos serviços e pela consolidação da RMC como um pólo nacional de ciência, tecnologia e inovação, intensificando a rede de relações com o setor produtivo. $\mathrm{O}$ outro eixo de dinamismo da economia paranaense vem sendo sustentado pelos recentes investimentos e pelo potencial de expansão do agronegócio no Estado do Paraná. Faz-se necessário visualizar a concentração setorial e espacial das atividades industriais, através da tabela 1, a seguir, desenvolvida pelos pesquisadores, para que seja possível fazer algumas análises pertinentes.

Ao analisar a primeira tabela, observa-se que a Região Metropolitana Sul-Curitiba concentra aproximada-

Tabela 1: Regiões, número de firmas em 2000, número de empregos em 1995 e 2000 e participação do valor adicional estadual, em percentagem de evolução comparada entre 1990, 1995 e 2000.

\begin{tabular}{|c|c|c|c|c|c|c|c|c|}
\hline \multirow{2}{*}{$\mathrm{N}$} & \multirow[t]{2}{*}{ DESCFICÄO DA FEGIÄO } & \multicolumn{2}{|c|}{ FIFMAS 2000} & \multicolumn{2}{|c|}{ EMPFEGOS } & \multicolumn{3}{|c|}{$\begin{array}{l}\text { PAFTICFACAO DO TALOR } \\
\text { ADICIONAL ESTADUAL } \%\end{array}$} \\
\hline & & FAIS & SEFA & 1995 & 2000 & 1990 & 1995 & 2000 \\
\hline 01 & Me tropolitana Notte-Fatanagua & 390 & 332 & 4.941 & 7.739 & 3,42 & 3,80 & 6,06 \\
\hline 02 & Me tropolitana Sul-Cutitiba & 5.752 & 4.217 & 113.906 & 124624 & 51,09 & 54,35 & 49,55 \\
\hline 03 & Potnta Grosa-Castro & 999 & 676 & 25.269 & 25.438 & 7,33 & 11,15 & 13,60 \\
\hline 04 & Itrati-Utriä o da Witótia & 969 & 766 & 13.727 & 16.053 & 2,10 & 2,27 & 2,60 \\
\hline 05 & $\mathrm{~J}$ an axezintho-S atato Antonio Platita & 413 & 297 & 5.826 & 6.919 & 1,12 & 1,08 & 1,10 \\
\hline 06 & Cornélio Proo ópio-B atude it atutes & 263 & 195 & 3.854 & 5.188 & 2,37 & 0,67 & 0,66 \\
\hline 07 & Londrina-Cambé & 2.082 & 1.693 & 36.391 & 45.097 & 8,37 & 8,18 & 8,63 \\
\hline 08 & Aprox aratca-Iт aiporä & 738 & 617 & 10.746 & 11.032 & 2,43 & 1,81 & 1,85 \\
\hline 09 & MI atitngat $-S$ as at1di & 1.671 & 1.434 & 22.746 & 26.958 & 6,42 & 4,04 & 4,07 \\
\hline 10 & F axanawif-Loatrda & 491 & 403 & 6.055 & 8.255 & 0,57 & 0,62 & 1,11 \\
\hline 11 & U mrn-7asatra- Cianott & 1.029 & 868 & 12.414 & 15.163 & 1,30 & 1,67 & 1,61 \\
\hline 12 & Campo Moutá o-Goicen & 420 & 303 & 5.913 & 5.840 & 2,28 & 0,90 & 0,84 \\
\hline 13 & Cascawel-Foz do Igrapu & 1.105 & 866 & 11.623 & 14.276 & 2,50 & 2,52 & 2,04 \\
\hline 14 & Tole do-Mateohal Candido Fotrdon & 822 & 563 & 8.626 & 13.683 & 3,28 & 2,04 & 2,02 \\
\hline 15 & $F_{\text {tamriseo Belträo-Pato Bratreo }}$ & 908 & 706 & 9.633 & 15.119 & 1,35 & 1,85 & 1,85 \\
\hline \multirow[t]{2}{*}{16} & Grtax apuawa-Fitanga-P altma s & 872 & 718 & 12219 & 14.836 & 4,06 & 3,06 & 2,41 \\
\hline & Total & 18.933 & 14.654 & 304.089 & 356220 & 100,00 & 100,00 & 100,00 \\
\hline
\end{tabular}

Fonte: IPARDES, com base nos dados da RAIS/MTE E SEFA, 2004 (apud CUNHA et al., 2004). 
mente a metade do valor adicionado da indústria do Paraná na década de 90 . A partir da segunda metade da década, detecta-se uma relativa desconcentração das atividades industriais em favor principalmente da Região Metropolitana Norte/Paranaguá, que aumenta a sua participação de 3,4\% em 1990, para 3,8\% em 1995 e 6,1\% em 2000. O crescimento do emprego segue a mesma trajetória.

Já, a Região de Ponta Grossa-Castro se destaca no período pelo elevado crescimento na participação no valor adicionado da indústria, que passa de 7,33\% em 1990 , para 11,15\% em 1995 e 13,6\% em 2000. Entretanto, a mesma tendência não ocorre em termos do crescimento na participação do emprego.

Selecionando os principais segmentos industriais especializados, os autores observaram uma forte concentração setorial e regional ao longo da década. A participação destes segmentos no valor adicionado da indústria do Estado, passa de 33\% em 1990, para 51\% em 1995, atingindo $58 \%$ em 2000. Por conta destes dados, parece não ficar difícil de perceber a existência do processo de concentração da indústria metal-mecânica na região metropolitana Sul/Curitiba. A tabela 2 mostra algumas das principais aglomerações industriais especializadas no Estado do Paraná, entre 1990, 1995 e 2000.

Observa-se, na tabela 2 , que os índices de crescimento dos setores industriais, que formam os eixos pro- dutivos e de fornecimento de insumos ou matérias primas para a sustentação da concentração industrial na Região Metropolitana Sul-Curitiba, têm sido bastante positivos, tal como objetiva a formação dos clusters automotivos na RMC.

Por exemplo, no segmento automotivo e de autopeças, específico, a participação do pólo automotivo na Região Metropolitana Sul passa de 6,08\% em 1990 , para 8,61\% em 1995 para e 12,81\% em 2000. Os demais segmentos da indústria metal mecânica, material eletromecânico e de comunicações, bem como a indústria mecânica e de máquinas e equipamentos elevam sua participação. Lembra-se que todos estes segmentos concentram-se espacialmente na Região Metropolitana Sul, podendo ser, portanto, caracterizado como uma estratégia de aglomeração industrial e locacional de um cluster.

Diante do exposto, Cunha et al. (2004, p. 11) concluem que "alguns dos eixos de transformações estruturais espaciais apresentados já estão consolidados regionalmente e encontram-se envolvidos em um ambiente institucional e de produção com capacidade endógena de sustentação, consolidados pelas vantagens de aglomeração, da interação e da eficiência coletiva”. Contudo, prosseguem os autores pesquisadores com um alerta importante:

TABELA 2: Principais aglomerações industriais especializadas do Paraná, em percentagem de crescimento comparado.

\begin{tabular}{|c|c|c|c|c|}
\hline Fegiöes & DESCFICAO SEGM ENTOS & 1990 & 1905 & 2000 \\
\hline WIe tropolitatas Sul-Cuzitiba & Automónel, utilitirio, o atrithhäo e atribus & 2,96 & 5,52 & 9,14 \\
\hline Me tropolitatas Sul-Cuxitiba & Autopeģa & 4,12 & 3,09 & 3,67 \\
\hline Foxta Grossa-Castro & Celulose, papel e papeläo & 1,69 & 5,81 & 5,10 \\
\hline Potrta Grossa-Castro & Etrloalagem de papel e papeläo & 0,00 & 0,00 & 2,83 \\
\hline Gluatapina va-Fitatrga-Paltras & Celulose, papel e papeläo & 1,18 & 1,01 & 0,94 \\
\hline Metropolitata Norte- & Cimetto & 1,63 & 1,74 & 238 \\
\hline We tropolitatas Sul-Curitiba & Attefato de oitrento & 0,70 & 0,86 & 0,65 \\
\hline Me tropolitatas Sul-Curitiba & L.ämitra e ohapa de madeira & 0,72 & 1,44 & 232 \\
\hline Me tropolitatas Sul-Curitiba & Ma terial elétric o e ele trôtrico & 1,30 & 1,25 & 2,15 \\
\hline We tropolitatas Sul-Curitiba & 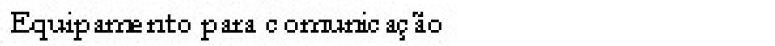 & 2,34 & 5,99 & 1,37 \\
\hline Me tropolitatas Sul-Curitiba & Elettodornétio & 0,58 & 2,62 & 1,72 \\
\hline Me tropolitata Sul-Curitiba & Sidetuxgia, trotaluxgia e usitragetrn de metal & 1,56 & 1,25 & 1,45 \\
\hline We tropolitama Sul-Curitiba & 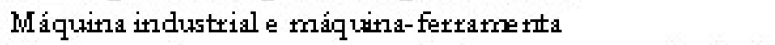 & 1,28 & 1,40 & 1,64 \\
\hline Me tropolitana Sul-Curitiba & Tratox e equpanento para agricultura e consturgäo civil & 0,76 & 1,05 & 1,00 \\
\hline We tropolitana Sul-Curitiba & Meo âtuicas diversas & 0,02 & 0,04 & 0,86 \\
\hline MIe tropolitatas Sul-Curitiba & Equip ancento para energia elétris a & 0,52 & 0,96 & 0,86 \\
\hline We tropolitatas Sul-Curitiba & Equip atre trto para itrstalapio itritustrial o otnetoial e & 4,09 & 1,63 & 0,77 \\
\hline Me tropolitatas Sul-Curitiba & Aparelho e itrstuntre nto médio o-hospitalax & 1,25 & 0,79 & 0,92 \\
\hline Metropolitata Norte- & Fertilisante e defensivo & 0,23 & 0,57 & 1,82 \\
\hline WIetropolitatas Sul-Curitiba & L.arritado e attefatos de plastie o & 1,27 & 0,74 & 1,70 \\
\hline L.oxtdritra- Cambé & Etrubalagetrn plastio a & 0,15 & 0,44 & 0,81 \\
\hline We tropolitatas Sul-Cutitiba & Etrbalagem plástio a & 0,37 & 1,36 & 0,77 \\
\hline We tropolitatas Sul-Curitiba & Quimio os dimersos & 1,69 & 1,94 & 1,69 \\
\hline We tropolitanas Sul-Curitiba & Fexfumaria e cosmétio o & 0,10 & 0,56 & 1,17 \\
\hline We tropolitatas Sul-Curitiba & Ediğă irryte s săo e te produg̨a & 0,61 & 1,48 & 0,95 \\
\hline
\end{tabular}

Fonte: IPARDES com base nos dados da SEFA, 2004 (apud CUNHA et al., 2004). 
No entanto, os resultado até agora apresentados com a metodologia aplicada e as informações utilizadas, não possibilitam um diagnóstico aprofundado do potencial de crescimento e sustentabilidade desses arranjos, seu grau de organização, estrutura produtiva, características tecnológicas, potencial de mercado, grau de interação, relações e vínculos de cooperação e interdependência intra empresas e destas com instituições de pesquisa. (CUNHA et al., 2004, p. 12).

O alerta dos autores vem ao encontro da problemática levantada pelo autor deste artigo, quando questiona a eficácia da maturação dos aglomerados industriais localizados na RMC. Sabe-se, que a consolidação de alguns arranjos produtivos distribuídos espacialmente na economia paranaense depende da ação conjunta do setor público e privado para incrementar quantitativa e qualitativamente os serviços na área de ciência e tecnologia e serviços técnicos especializados, o ensino e formação de mão-deobra tecnicamente preparada para atender aos requisitos da nova indústria, os serviços de intermediação financeira e a existência de infra-estrutura física de apoio à produção e comercialização.

Tal preocupação está baseada nos fundamentos do estudo do ciclo de vida de um produto, podendo esta lógica ser igualmente aplicada no estudo do ciclo de vida de um segmento de mercado, conforme postula Kotler (2000, p. 326). O conceito de ciclo de vida do produto ou de um segmento de mercado, apresentado no gráfico 1 , de acordo com o mesmo autor, está sustentado por quatro variáveis. São elas:

1) os segmentos de mercados têm uma vida limitada, tais como os produtos que fazem parte deste segmento;

2) as vendas dos produtos, igualmente seus segmentos de mercados atravessam estágios distintos, sendo que cada um apresenta desafios, oportunidades e problemas diferentes para seus gestores;

3) os lucros sobem e descem em diferentes estágios do ciclo de vida de um produto ou de um segmento de mercado;

4) os produtos, igualmente aos segmentos de mercado requerem constantemente estratégias de marketing, novas fontes de financiamentos, de produção, de materiais inovadores e de recursos humanos diferentes a cada estágio de seu ciclo de vida.
Sob esta perspectiva, o ciclo de um produto ou de um segmento de mercado, como é o caso da indústria automotiva aglomerada na RMC, passa por quatro fases. São elas: a) introdução; b) crescimento; c) maturidade; d) declínio.

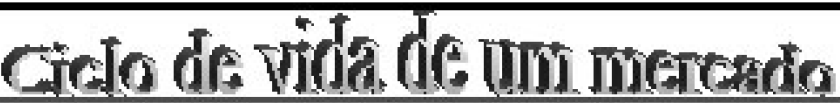

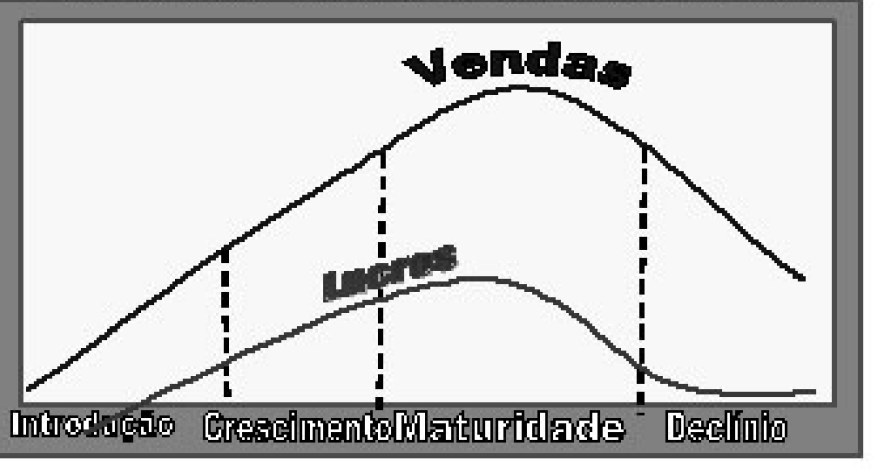

Gráfico 1: Ciclo de vida de um mercado

onte: Kotler (2000, p. 326).

A fase da introdução é caracterizada por um período de baixo crescimento em vendas, uma vez que o produto deste segmento está sendo introduzido no mercado. Normalmente, neste estágio, as empresas não obtêm lucros, por conta dos pesados custos iniciais e um volume alto de capital no investimento do negócio.

Já, no período seguinte, a do crescimento, é caracterizada, quando a atividade apresenta pequenas margens de lucro, devido a aceitação do consumidor e da conquista de uma fatia do mercado. É, igualmente, a fase onde as estatísticas comprovam uma relativa elevação dos índices de representatividade dentro do segmento.

A fase de maturidade é diferenciada das anteriores, pois é quando o produto ou o segmento de mercado prossegue, por um certo período, com aumento de vendas e de lucros, alcançando o ponto máximo da curva, podendo manter-se constante, por um outro período; mas logo após, é percebida um relativo declínio. Isso porque o produto ou o segmento de mercado já conquistou a aceitação da maioria dos compradores potenciais. Como conseqüência, os lucros tendem a manter-se estáveis e/ou declinam, devido à competição acirrada.

É, na etapa de maturação, que os altos executivos, que gerenciam este segmento de mercado, precisam tomar determinadas decisões empresariais. Pela lógica capitalista, ou seja, de buscar incessantemente não apenas o lucro, mas a maximização do lucro, os empreendedores terão dois caminhos a seguir: 1) não mais produzirão o bem e abandonam o segmento de mercado e buscam outro que ofereça uma maior rentabilidade; ou 2) deve- 
rão inovar seus produtos ou dar uma nova dinâmica ao segmento de mercado industrial.

Após o declínio, dá-se continuidade à decadência do segmento, já iniciada no final da fase anterior, ou seja, percebe-se um período em que as vendas mostram uma queda vertiginosa e os lucros desaparecem. Os gestores desavisados, nesta fase (que não é o caso das CMNs capitalistas globais), não conseguem passar adiante seus negócios, contabilizando cada vez mais prejuízo nas suas atividades.

Por conta destes entendimentos sobre o ciclo de vida de um produto ou de um segmento de mercado, pode-se fazer uma analogia com relação à atuação do cluster automotivo, que concentrou suas atividades produtivas, por conta da aglomeração industrial, na RMC, o que despertou os questionamentos, já anteriormente, formulados. Permita o leitor, apenas relembrá-los das problemáticas levantadas:

a) a preocupação deve apenas se centralizar nas montadoras que estão instaladas fora da polarização da metrópole paulista?

b) será que as montadoras que escolheram tecnicamente localizar-se na RMC não correm igualmente o mesmo risco de não serem sustentáveis economicamente, no longo prazo, após os incentivos fiscais recebidos pelo governo do Estado do Paraná?; e

c) não será necessário, que as instituições responsáveis pela atração destes investimentos estrangeiros, para o Estado do Paraná, ainda precisem implementar novas políticas institucionalizadas para a maturação destes empreendimentos?

Sabe-se, o que está sendo buscado nesta análise não é questionar sobre a aceitação do produto automóvel pela sociedade brasileira; mas sim, o resultado econômico da estratégia de aglomeração industrial das companhias multinacionais do setor automotivo na RMC, uma vez que estas organizações trabalham dentro de uma lógica capitalista, o lucro incessante.

Pois bem, pelos dados apresentados anteriormente por Cunha (2004) percebe-se que o segmento industrial automotivo, concentrado na Região Metropolitana SulCuritiba, está vivenciando a segunda fase do ciclo de vida do segmento de mercado automotivo, localizado na RMC, ou seja, a fase de crescimento, tal como foi demonstrado nas tabelas 1 e 2 . Acredita-se que o segmento seguirá sua trajetória, tal como evidenciado no quadro 1. E, é, exatamente na fase seguinte, a fase da maturidade, que pairam algumas dúvidas.

Em primeiro lugar, quando este segmento de mercado atingir o ponto máximo da curva, portanto, no ponto máximo da obtenção de lucro da atividade, por conta da aglomeração industrial, poderá coincidir com o momento do término dos benefícios fiscais e institucionais, colocando as CMNs, sem sombra de dúvidas, em risco de sustentabilidade econômica de suas atividades na RMC.

O que acontecerá depois com estas empresas aglomeradas? Quais serão as decisões que os gestores do cluster automotivo tomarão? Pensa-se ser possível diagnosticar duas resposta-hipóteses. Primeira, deverão formar novas aglomerações industriais em outras localizações espaciais em condições para reiniciar suas atividades, objetivando a maximização de seus lucros em novas regiões periféricas sedentas de novos investimentos para promover o desenvolvimento econômico regional; ou segunda, deverão buscar do Estado do Paraná e das instituições de apóio ao desenvolvimento, novos estímulos para a região já concentrada, novos fatores de produção mais competitivos, que propiciem à retomada dos lucros ou que, no mínimo, eles sejam constantes, se não no ponto máximo da curva, próximo a ele.

$\mathrm{Na}$ resolução das duas respostas-hipóteses parece ser relevante o papel das autoridades e das instituições sociais que promoveram a atração desses investimentos para a RMC. Caso não se faça algo para minimizar o efeito da primeira hipótese, a sociedade e o Estado terão problemas conjuntos com a diminuição do emprego, diminuição dos tributos, uma pressão política e social por ter investido num segmento de mercado, e que após cessar os lucros, os empreendimentos tendem a se transferir para outras localidades. Enfim, um grande prejuízo social e político muito alto para os gestores vigentes.

Analisando a segunda hipótese, novamente as autoridades e as instituições sociais de apóio precisam entrar em cena para poder negociar novas formas de incentivo, alocando novos recursos produtivos, financeiros, creditícios, flexibilizando os direitos sociais do trabalhador, as leis ambientais, agora para a manutenção das atividades do cluster na RMC, e minimizar os efeitos negativos da saída das empresas.

Observa-se, que nas duas possíveis hipóteses levantadas, o papel do Estado é ainda relevante para a resolução das questões empresarias e sociais, não somente pela atração, mas igualmente pela manutenção das CMNs na RMC, com o objetivo de manter as atividades produtivas no Estado, seus possíveis ganhos sociais, tributários e políticos. Tais estratégias fazem lembrar as reflexões de Wallerstein (2002, p. 37), quando sintetiza que "os Estados podem agravar ou mitigar o sofrimento, mediante alocação de recursos, o grau de proteção conferido aos direitos e as intervenções nas relações sociais entre diversos grupos".

Partindo de tal raciocínio, observa-se que o governo sofrerá pressões constantes pela intervenção do Estado, de forma racional e eficiente, para manter e gerar riquezas, modernizar sua infra-estrutura, promover a 
internacionalização do Estado, regulamentar as condições de trabalho, atrair os investimentos diretos estrangeiros, tornar o estado mais competitivo que os demais da Federação, estabelecer estruturas de transferência de renda, e para o Estado legalizar e legitimar as atividades de organização das classes envolvidas.

Pois bem, diante de tal fato, pretende-se terminar esta reflexão, com algumas problemáticas que o Estado e as instituições de apoio precisarão, juntamente com a sociedade organizada, resolver para poder manter e promover a maturação, de forma contínua, das CMNs na RMC. Eis algumas questões, que os tomadores de decisões governamentais e institucionais terão de lidar. Tratam-se de questões de fundamental importância para a continuidade da base do cluster automotivo, centralizado na RMC:

a) existe estímulo para as trocas de informações pelas instituições responsáveis pela disseminação dos avanços tecnológicos?

Em muitos casos, a manutenção desse tipo de arranjo precisa ser estimulada e para tanto os órgãos de desenvolvimento devem estar preparados para atuar eficazmente. $\mathrm{O}$ surgimento de uma atmosfera propícia à inovação, exige que os indivíduos estejam constantemente trocando idéias e informações. Em termos mais específicos, pode-se sugerir aqui a organização de fóruns, seminários, promoção de palestras e outras;

b) o Estado tem promovido a sustentabilidade econômica para as pequenas e micro empresas, que formam uma estrutura de empresas fornecedoras de matérias primas, por conta da redução da carga tributária, investimento na infra-estrutura, que diminua o custo de transporte e de logística?

Esta pergunta torna-se importante, porque os órgãos articuladores de um cluster devem estar permanentemente atentos à questão da rede de fornecedores. Eles devem garantir tanto a proximidade dos fornecedores como também assegurar que a própria forma de operação desses fornecedores seja acessível para as pequenas empresas;

c) o Estado tem promovido cursos de aperfeiçoamento dos processos produtivos, propiciado investimento em pesquisa e desenvolvimento para as novas demandas do setor automotivo internacional?

Uma política de fomento à formação de clusters, deve orientar suas intervenções no sentido de promover o constante aperfeiçoamento dos processos produtivos e da qualidade dos produtos. Além do treinamento, incluem-se: a participação em feiras e demais eventos especializados (inclusive em países estrangeiros), a organização de missões de visitas aos mercados compradores e outros;

d) o Estado, por intermédio das universidades públicas federal e estaduais, tem sido eficiente nas gestões de inovações de comunicação produtiva?

Procura-se alicerçar a sustentabilidade do processo na comunidade (parcerias institucionais em todos os níveis - federal, estadual e municipal - e atores locais (agentes da área considerada, apoiados na força de suas lideranças)); e direciona o esforço de investimentos e de ações em função de atividades econômicas que possuem potencial real de desenvolvimento e de competitividade, inclusive em mercados internacionais;

e) o Estado tem cumprido o seu papel para a manutenção dos projetos existentes?

Os papéis apropriados do governo são: Apoiar as iniciativas de identificação das manifestações espontâneas embrionárias de clusters; Estabelecer um ambiente econômico e político estável e previsível; Aumentar a disponibilidade, qualidade e eficiência de inputs de caráter geral e das instituições; Criar um contexto que incentive inovações e avanços; Reforçar a formação de cluster e sua constante melhoria e avanços na economia; Criar e comunicar uma visão econômica nacional, positiva, distinta e atuante, que possibilite mobilizar os cidadãos para a ação; e

f) e quanto ao processo de sistema nacional de inovação, o Estado tem fomentado o aprendizado interativo, base do sistema de inovação?

Garcez (2000) alerta que conhecimento e aprendizado são, respectivamente, recurso e processo fundamentais na economia, na sociedade atual, e instrumentos de matéria prima para as CMNs. São os elementos e as relações presentes em determinados sistemas que poderão determinar a capacidade de aprendizado de um país, região ou localidade. Tais instrumentos possibilitam a flexibilidade perante as pressões de mudança nos ambientes.

\section{CONSIDERAÇÕES FINAIS}

Este trabalho teve como ponto de partida, as pesquisas de Lemos e Ferreira (2004) e Cunha et al (2004), que analisaram as novas estratégias locacionais das $\mathrm{CMNs}$ automotivas e o sistema nacional de inovação na periferia industrializada. Por conta, destas pesquisas, surgiu o objetivo deste trabalho, Objetiva-se neste trabalho fazer uma análise sobre as futuras políticas complementares 
para a maturação dos Clusters automotivos, implantados na Região Metropolitana de Curitiba - RMC. Quanto aos questionamentos levantados, foi possível chegar a algumas reflexões, como será descrito, a seguir:

Parece ser prudente, que todas as análises dos investimentos, promovidos pelo estado do Paraná, pelas instituições de apoio ao crescimento econômico e pela sociedade paranaense sejam, constantemente, avaliadas sobre a manutenção, de forma eficaz, das CMNs automotivas na RMC. Caso contrário, o custo social já dispendido será elevado. Assim, a preocupação de toda sociedade do Estado do Paraná é focar também a atenção para as montadoras instaladas na RMC.

Percebeu-se, caso não esteja acontecendo inovação e fortalecimento das bases de sustentação do cluster automotivo, localizados na RMC, o Estado corre o risco de não poder fornecer, num futuro muito próximo, recursos ou fatores de produção de sustentação deste modelo de produção, tornando insustentáveis economicamente, as empresas participantes deste processo, no médio e longo prazo. Sabe-se, que faltam incentivos às pesquisas científicas para fortalecer o sistema nacional de inovação.

Naturalmente, é preciso que o Estado, com o apóio das universidades, das agências de fomentos, das incubadoras tecnológicas, investa em novos núcleos de inovação tecnológica, com objetivo de antever as necessidades do sistema de inovação nacional, propondo tecnologias pró-ativas. Igualmente, faz-se necessário, por parte dos gestores do governo, bem como das instituições de apóio, que, em conjunto, busquem novas iniciativas de instrumentos de apóio, de cooperação, de forma constante, à maturação das atividades das CMNs, na RMC, não necessariamente apenas pela, já conhecida, abdicação de tributos, mas que discutam e busquem novas formas de parceria Estado e capital, de jornadas flexíveis de trabalho.

Por fim, as CMNs, aglomeradas na RMC, parecem estar necessitando de maior e contínua investigação científica, pois mostram uma certa vulnerabilidade no ciclo de vida do segmento industrial automotivo, mostrando que este segmento industrial não está eficazmente consolidado, sustentado economicamente. Tal entendimento remete à algumas providências que precisam ser tomadas hoje ou num futuro muito próximo.

Espera-se que esses entendimentos e reflexões aqui desenvolvidas possam servir de instrumentos de análises para os gestores públicos e demais instituições dos demais estados federativos do Brasil. Que possam ser, igualmente, de grande valia para as demais sociedades que almejam atingir um status de Estado moderno, ao atrair para o seu espaço geográfico, um complexo industrial de montadoras de automóveis, que ostente o símbolo de modernidade, do crescimento econômico, mesmo que à custa da dependência institucional do Estado e da própria sociedade. Eis a escolha democrática de cada estado federativo brasileiro. Eis o desafio.

\section{REFERÊNCIAS}

ALBUQUerQue, E. M. Análise da Performance Produtiva $e$ Tecnológica dos Clusters Industriais na Economia Brasileira. Nota Técnica n. 28/00. Rio de Janeiro: IE/UFRJ, junho, 2000.

ALTENBUNG, T. \& J. MAYER-STAMER. How to promote clusters: experiencies from Latin América. World Development. USA, 1999.

BECK, Ulrich. Modernização reflexiva: política, tradição e estética na ordem social moderna. São Paulo: UNESP, 1997.

CASTELLS, Manuel. A sociedade em rede. 6. ed. vol. 1. São Paulo: Paz e Terra, 2003.

CHESNAIS, François. A mundialização do capital. São Paulo: Xamã, 1996.

CROCCO, Marco Aurélio; et al. Metodologia de identificação de arranjos produtivos locais. Texto para discussão. Belo Horizonte: UFMG/Cedeplar, 2003.

CUNHA, Sieglin Kindl; OLIVEIRA, Maria Aparecida de; CUNHA, João Carlos. Clusters: Novo padrão de especialização da indústria paranaense na década de 90. Palestra apresentada na VI SemeAD, Curitiba, 2004.

DUPAS, Gilberto. Economia global e exclusão social: pobreza, emprego, estado e o futuro do capitalismo. São Paulo: Paz e Terra, 1999.

FLORIANI, Dimas. Conbecimento, meio ambiente \& globalização. Curitiba: Juruá, 2004.

GARCEZ, Cristiane M. D'avila. Sistemas locais de inovação na economia do aprendizado: uma abordagem conceitual. v. 7, n. 4, p. 351- 366. Revista do BNDES. Rio de Janeiro: BNDES, 2000.

GIDDENS, Anthony. As conseqüências da modernidade. 6. reimp. São Paulo: Editora UNESP, 1991.

GUALDA, Neio Lúcio Peres. Alguns requisitos para a formação de "Clusters". Programa de Mestrado em Economia da Universidade Estadual de Maringá - UEM. Entrevista. Maringá, setembro, 2004.

KOTLER, Philip. Administração de Marketing. A edição do novo milenio. 10. ed. São Paulo: Prentice Hall, 2000.

KRUGMAN, P. Geography and Trade. Cambridge, MA: MIT Press, 1991.

LEFF, E. Espacio, lugar Y tiempo; la reapropriación social de la naturaleza y la construcción local de la racionalidad. In: Desenvolvimento e Meio Ambiente. Teoria e Metodología em Meio Ambiente e Desenvolvimento. n. 1. Revista. Curitiba: Universidade Federal do Paraná - UFPR, 2000.

LEMOS, M. B.; FERREIRA, F. Novas estratégias locacionais das CMNs automotivas e sistema nacional de inovação na periferia industrializada. Disponível em: www.ie.ufrj.br/globelics/ pdfs/GLOBELICS 0092_Mauro.pdf.>. Acesso em 31/ago/ 04 .

MARSHALL, Alfred. Princípios de Economia. (Série os Economistas). São Paulo: Abril Cultural, 1982.

SANTOS, Boaventura de Sousa. A Globalização e as ciências sociais. 2. ed. São Paulo: Cortez, 2002.

SCHEFFER, Álvaro Luiz. Caminhos para uma política industrial eficaz. In: Observatório da Indústria. Revista. n. 2, p. 30-31. Curitiba: FIEP, ago/set, 2004. 
SUZIGAN, Wilson. Aglomerações industriais como foco de politicas. Texto da aula magna do XVIII Encontro Nacional de Economia da ANPEC. Campinas: Unicamp, dez, 2000-a.

; FURTADO, João; GARCIA, Renato; SAMPAIO, Sér-

gio E. K. Aglomerações industriais no Estado de São Paulo. Campinas: Unicamp, 2000-b.

WALLERSTEIN, Immanuel. Após o liberalismo. Petrópolis Rio de Janeiro: Vozes, 2002. 